See Article page 311.

\section{Commentary: Living related lung transplantation in children}

\author{
Pirooz Eghtesady, MD, PhD
}

"Necessity is the mother of invention," so the saying goes. In this issue of JTCVS Techniques, Oto and colleagues ${ }^{1}$ once again provide an elegant alternative for living related lung transplant in infants who otherwise have no other options. The accompanying video is also well done and clearly explains the steps taken one by one.

Indeed, the history preceding this innovative paper is one filled with many "firsts" when lobar lung transplantation was undertaken, in response organ donor shortages, by Starnes and colleagues at Stanford University Medical Center, under the guidance of the late legend, Dr Norman Shumway. ${ }^{2}$ It was the early 1990s, and the Toronto Lung group had shown much success with single-lung transplantation for pulmonary fibrosis. ${ }^{3}$ The Stanford group took the next step to assess the potential for single-lung transplants in patients with pulmonary hypertension; at the time, it was deemed the likely significant perfusion-ventilation mismatch would make such an operation unsafe and unlikely to succeed. The Stanford program had evolved from an extensive experience gained from heart-lung transplantation for both adults and children. As a consequence of this program and due to donor shortages, many of the original heart-lung candidates became single-lung candidates.

Three of these early single-lung recipients were children who received lobar transplants, 2 of which were living related. On October 27, 1990, an 11-year-old patient with bronchopulmonary dysplasia received the right upper lobe of her mother as the right lung simultaneously with closure of an atrial septal defect. A second child, a 3-year-old

\footnotetext{
From the Department of Surgery and Pediatric Cardiothoracic Surgery, Washington University School of Medicine; and Heart Center, St Louis Children's Hospital, St Louis, Mo.

Disclosures: The author reported no conflicts of interest.

The Journal policy requires editors and reviewers to disclose conflicts of interest and to decline handling or reviewing manuscripts for which they may have a conflict of interest. The editors and reviewers of this article have no conflicts of interest.

Received for publication July 15, 2020; revisions received July 15, 2020; accepted for publication July 17, 2020; available ahead of print July 20, 2020.

Address for reprints: Pirooz Eghtesady, MD, PhD, Washington University/St Louis Children's Hospital, One Children's Place, Suite 6120, Campus Box 8234, St Louis, MO 63110 (E-mail: eghtesadyp@wustl.edu).

JTCVS Techniques 2020;3:315-6

2666-2507

Copyright ( $) 2020$ The Authors. Published by Elsevier Inc. on behalf of The American Association for Thoracic Surgery. This is an open access article under the CC BY-NCND license (http://creativecommons.org/licenses/by-nc-nd/4.0/).

https://doi.org/10.1016/j.xjtc.2020.07.011
}

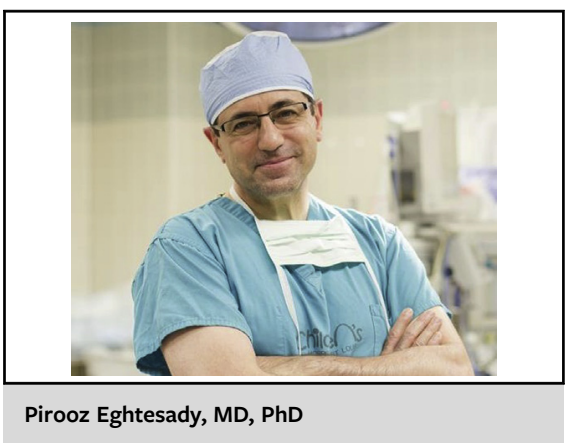

\author{
CENTRAL MESSAGE \\ Developed in the United States, \\ living related lung transplant is \\ now mainly limited to Japan, \\ where average waiting times \\ exceed years. This has resulted in \\ continued innovative operative \\ procedures.
}

patient with Eisenmenger syndrome secondary to a ventricular septal defect, received the middle lobe of her father concomitant with ventricular septal defect closure. While the first child did well, the second unfortunately died from reperfusion pulmonary edema following surgery. In the same short interval, an infant underwent a left lung transplant for which the left upper lobe of a 2-year-old deceased donor was used. These early experiences also showed despite ventilation-perfusion mismatch with the new lung receiving more than $90 \%$ of total blood flow but only $50 \%$ of ventilation, functionally it did fine.

Over the ensuing decade, McLean and colleagues ${ }^{4}$ further refined the living lobar lung transplantation with version 2.0: 3 simultaneous operations with 2 healthy donors, each contributing a single lower lobe (one the lower right and the other lower left) and the recipient operation occurring shortly thereafter with minimal ischemic times. This was indeed quite an enterprise. The success of these operations required an expert knowledge of lung anatomy to avoid incidental injuries (eg, to the middle lobe or the lingula) during the donor operations. Even the postoperative management of the patients was more demanding than standard thoracic patient. For example, this author recalls as a young surgical house-staff being instructed on the nonconventional chest tube management in the postoperative period to avoid unintended impaired lung deflation due to size constraints and lung mechanics for the donor lobes. 
Often the drains remained in place for a few weeks due to persistent fluid accumulation from the size mismatch.

In time, living related lung transplantation became less common, with only a handful of cases performed in the United States since the early 2000s; there have been none reported to the International Society of Heart and Lung Transplantation since 2012. This was in part due to perceived relative balance of risk to donor and improved organ availability from alterations in allocation criteria in 2005 as well as lack of any evidence for greater benefit to the recipient despite the shorter ischemic times (in terms of lower likelihood of rejection or bronchiolitis obliterans). However, in some countries, particularly those in Asian continents, the imperative to continue to use living donors has remained due to both cultural as well as regulatory barriers for increased donor availability. For that reason, most of the published literature over the last decade comes from esteemed colleagues in Japan, Korea, and other innovative transplant units in Asia. Indeed, Oto and colleagues ${ }^{5}$ had previously performed living related middle lobe lung transplant in a 3-year-old patient with a combination of restrictive and obstructive lung disease secondary to graftversus-host following bone marrow transplantation.

Oto and colleagues have wisely converted a single-lower lobe into 2 effective lobes for the infant. This is critical, as the adult lower lobe usually would be too big for infants, resulting in challenges not only with chest closure but also likely increased airway resistance, atelectasis, and even hemodynamic instability. Indeed, donor graft size selection is paramount in living related lung transplantation. Some, such as the Kyoto group, have come up with even specific formulas based on forced vital capacity to determine what they call functional size matching. ${ }^{6}$ The conduct of the recipient operation can also be challenging; invariably, cardiopulmonary bypass support is needed in infants. Performing bilateral living related lung transplantation is no easy feat, as it requires significant human resources: 3 surgical teams and perhaps even a back-table team. Our center only completed 38 such transplants ${ }^{7}$ during the same era as work done at other centers, with essentially equivalent results both short term and long term.

It is unlikely the volume of such cases will increase significantly any time soon. Nevertheless, those interested in undertaking such procedures would be well served reading the detailed article from Oto and colleagues and reviewing their well-prepared video.

\section{References}

1. Oto T, Hikasa Y, Hagiyama A, Kobayashi M. Bilateral segmental lung transplantation for children: transplantation using split adult living-donor lower lobe. J Thorac Cardiovasc Surg Tech. 2020;3:311-4.

2. Starnes VA, Lewiston NJ, Luikart H, Theodore J, Stinson EB, Shumway NE. Current trends in lung transplantation. Lobar transplantation and expanded use of single lungs. J Thorac Cardiovasc Surg. 1992;104:1060-5; discussion 1065-6.

3. Toronto Lung Transplant Group. Unilateral lung transplantation for pulmonary fibrosis. N Engl J Med. 1986;314:1140-5.

4. McLean MK, Barr ML, Starnes VA. Living lobar lung transplantation. Op Tech Thor Cardiovasc Surg. 2007;1:47-56.

5. Oto T, Miyoshi K, Sugimoto S, Yamane M. Living related donor middle lobe lung transplant in a pediatric patient. J Thorac Cardiovasc Surg. 2015;149:E42-4.

6. Date H, Aoe M, Nagahiro I, Sano Y, Matsubara H, Goto K, et al. How to predict forced vital capacity after living-donor lobar-lung transplantation. J Heart Lung Transplant. 2004;23:547-51.

7. Sweet SC, De La Morena MT, Schuler PM, Patterson GA, Meyers BF, Schuller D, et al. Single center comparison of pediatric living donor lobar and cadaveric lung transplant. J Heart Lung Transplant. 2003;22:S145-6. 